\title{
Michel Jarrety, Paul Valéry
}

\section{Fabio Scotto}

\section{(2) OpenEdition}

\section{Journals}

\section{Edizione digitale}

URL: https://journals.openedition.org/studifrancesi/4799

DOI: 10.4000/studifrancesi.4799

ISSN: 2421-5856

\section{Editore}

Rosenberg \& Sellier

\section{Edizione cartacea}

Data di pubblicazione: 1 avril 2012

Paginazione: 181

ISSN: 0039-2944

\section{Notizia bibliografica digitale}

Fabio Scotto, «Michel Jarrety, Paul Valéry», Studi Francesi [Online], 166 (I | LVI) | 2012, online dal 30 novembre 2015, consultato il 19 novembre 2021. URL: http://journals.openedition.org/studifrancesi/ 4799 ; DOI: https://doi.org/10.4000/studifrancesi.4799

Questo documento è stato generato automaticamente il 19 novembre 2021.

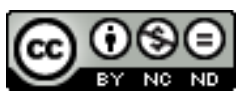

Studi Francesi è distribuita con Licenza Creative Commons Attribuzione - Non commerciale - Non opere derivate 4.0 Internazionale. 


\title{
Michel Jarrety, Paul Valéry
}

\author{
Fabio Scotto
}

\section{NOTIZIA}

MICHEL JARRETY, Paul Valéry, Paris, Fayard, 2008, pp. 1366.

1 Si deve a Michel Jarrety, professore di letteratura francese alla Sorbona e da trent'anni attivo sul fronte della critica valéryana, della quale è uno dei massimi esponenti contemporanei, questa monumentale biografia del poeta che, prima nel suo genere, muove dall'attività letteraria e dalle vicende private per estendere lo sguardo sull'attività pubblica e i ruoli molteplici che nel corso della sua intensa esistenza il poeta di Sète si è trovato ad esercitare. Mancava in effetti al catalogo novecentesco uno studio che cercasse di affrancare Valéry da una serie di luoghi comuni ai quali troppo spesso è stata ridotta la sua avventura, dalla crisi genovese alla filiazione mallarmeana, fino all'emulazione intellettualistica di Leonardo da Vinci in un'ostinata e quasi mistica ricerca del proprio funzionamento intellettuale del quale lo sterminato repertorio dei Cahiers è la prova più tangibile ed estrema.

2 Strutturato in sei parti per un totale di cinquantasette capitoli, che cronologicamente abbracciano il periodo che va dal 1871, alle soglie quindi della Terza Repubblica, fino alla fine della Seconda Guerra Mondiale, il volume, che è corredato di numerose illustrazioni fotografiche e attinge ad un cospicuo repertorio di documenti inediti, è caratterizzato, oltre che da un'amplissima visione d'assieme sul rapporto fra le vicende storiche e culturali del tempo, che vede Valéry assurgere alla gloria, ma anche consumarsi in un'angoscia profonda solo in parte stemperata dalla funzione di ammirato e sollecitato ambasciatore culturale, grande oratore, docente e pensatore, anche da un'attenzione quasi maniacale per il dettaglio, inteso, secondo il richiamo a Lucien Leuwen di Stendhal fatto a p.9, come l'unica vera fonte di originalità e di verità. Jarrety ripercorre settimana per settimana la vita del poeta, dalla nascita agli inizi della carriera letteraria, per poi diffondersi sul vasto orizzonte degli incontri illustri e meno illustri di quello che definisce «Le Bossuet de la III ${ }^{e}$ République» (p. 817) per via del 
carisma "istituzionale" e accademico di cui gode, senza eludere alcun episodio della vita pubblica, ma anche costantemente attingendo ai carteggi e ai testi diaristici e intimi di auto-commento. Ne risulta una narrazione critica mai monotona, sempre sobria anche quando velata di garbata ironia, ricca di curiosità aneddotiche e spunti di riflessione e tesa a mostrare la figura dell'uomo nella sua complessità e pienezza oltre le apparenze e i luoghi comuni. Certamente l'A. non nasconde la sua personale interpretazione del percorso e della figura di Valéry, che è quella di chi lo riconosce personalità "storica" della sua epoca, per l'azione e l'influenza esercitata in vari ambiti, oltre che "letteraria". Bastino queste inquietudini del 1932 sull'avvenire dell'Europa a dare la misura dell'attenzione di Jarrety che neppure necessita di attualizzazione, dato che la contiene implicitamente in se stessa, come per triste ricorso storico vichiano: «L'âge des mélancolies commence, et cette tristesse personnelle va bientôt se doubler en une autre: celle de voir s'éloigner les espoirs qu'il [Valéry] mettait dans la conciliation européenne» (p. 816).

3 Sempre di Michel Jarrety segnaliamo anche la successiva edizione e cura critica di Souvenirs et réflexions di Paul Valéry (Paris, Bartillat, 2010, pp. 206), che raccoglie testi del periodo dell'entre-deux-guerres divenuti introvabili e a cavallo fra il tono epidittico dell'omaggio ad amici vivi o morti e la dolente inquietudine per il destino dell'arte e della cultura europee minacciate dall'avvento dei totalitarismi che condurranno alla Seconda Guerra Mondiale. In essi si ha piena misura della statura di quello che il curatore definisce non solo un poeta, ma «une sorte de passeur de culture en même temps qu'un analyste et un théoricien de cette culture à l'intérieur de laquelle la littérature continue, bien sûr, d'occuper une place centrale» (p. 11). 